\title{
A Solução POWERLINE Para o Sector Residencial
}

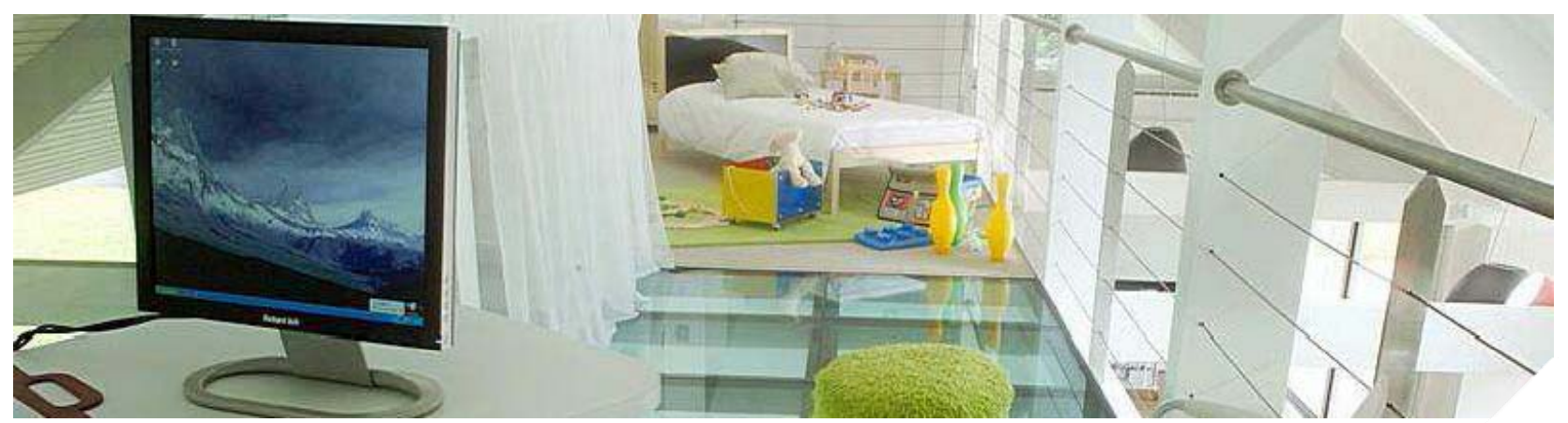

Introdução

Apesar de muito utilizada no sector industrial, a automação ainda não atingiu o mesmo patamar de implementação no sector doméstico. A evolução tecnológica leva a que quase todos os dias apareçam novos produtos que visam a implementação de sistemas domóticos que possibilitem o conforto, a segurança e a eficiência nas habitações. Contudo, quando se pretende instalar um sistema domótico com o objectivo de simplificar os processos numa habitação, a palavra que surge não é "simplicidade", mas sim "complicação".

Para além de a grande maioria das pessoas não estar familiarizada com as funcionalidades que um sistema domótico permite, existe sempre o pensamento que esses sistemas têm um custo elevado, o que de certa forma não é um pensamento errado. Se quanto ao aspecto do preço, não há muito a fazer, ele depende das leis do mercado e do custo da inovação, quanto à complexidade da instalação e utilização dos sistemas, trata-se de um pensamento induzido nas pessoas que não conhecem os sistemas domóticos e que facilmente se consegue desmistificar.

Os projectos de domótica nas habitações deveriam ser pensados aquando do projecto da habitação. No entanto, a realidade não é essa. A grande maioria das habitações não foi pensada para a instalação desses sistemas e só depois da instalação eléctrica estar efectuada e a habitação habitada é que se percebe que se precisava de ter mais alguma flexibilidade e funcionalidade na instalação. A evolução tecnológica permitiu desenvolver soluções para este tipo de situações. Hoje em dia não é necessário reconstruir a habitação para instalar sistemas domóticos. Existem soluções que usam a rede eléctrica já instalada e que permitem instalar funções domóticas na habitação.

\section{Funções usuais}

Não é preciso ter uma casa totalmente automatizada para que ela seja considerada "inteligente". Muitas vezes a busca por mais e mais automatização dos processos leva ao aumento da complexidade e ao inerente aumento do preço do sistema instalado. Quando se pretende dotar uma instalação com um sistema domótico, a primeira coisa que se deverá fazer é perceber o que realmente se pretende. Saber quais são as funções que realmente fazem sentido dotar de alguma "inteligência".

Um dos sistemas que numa habitação faz algum sentido ser comandado é o do sistema de estores e toldes.

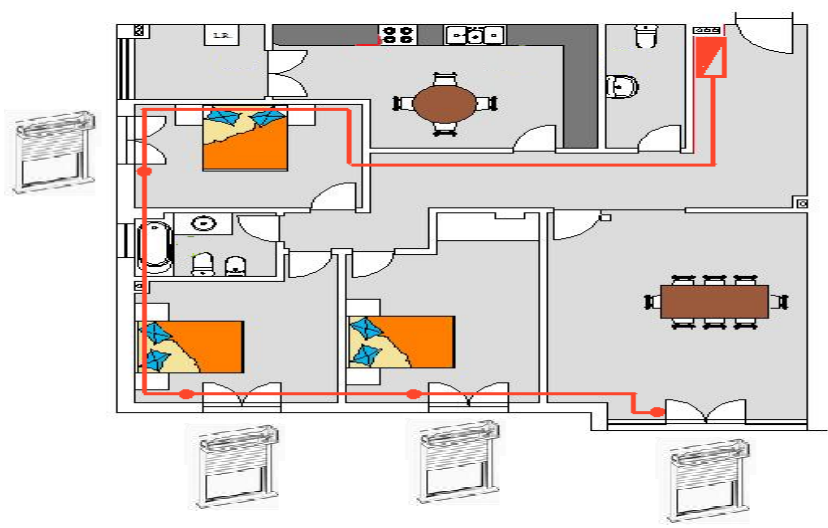

Fig.1 - Comando de estores com sistema PLC 


\section{ARTIGO TÉCNICO}

Poder abrir ou fechar os estores individualmente ou por grupos, ou fazer o comando de acordo com a quantidade de luz natural ou vento existente. Esta é uma função que para além do conforto que introduz, leva também ao aumento da eficiência energética da habitação.

A iluminação é outro dos sistemas que se deve dotar de alguma automatização.
A instalação de alarmes técnicos tais como a detecção de gases combustíveis, a detecção de monóxido de carbono, a detecção de inundação e a detecção de incêndios são funções que devem ser implementadas. A possibilidade de em caso de fuga de gás ou de inundação se poder actuar nas electroválvulas para se efectuar o corte do gás ou da água ou em caso de incêndio de fazer soar um alarme sonoro, são funções muito úteis numa habitação.
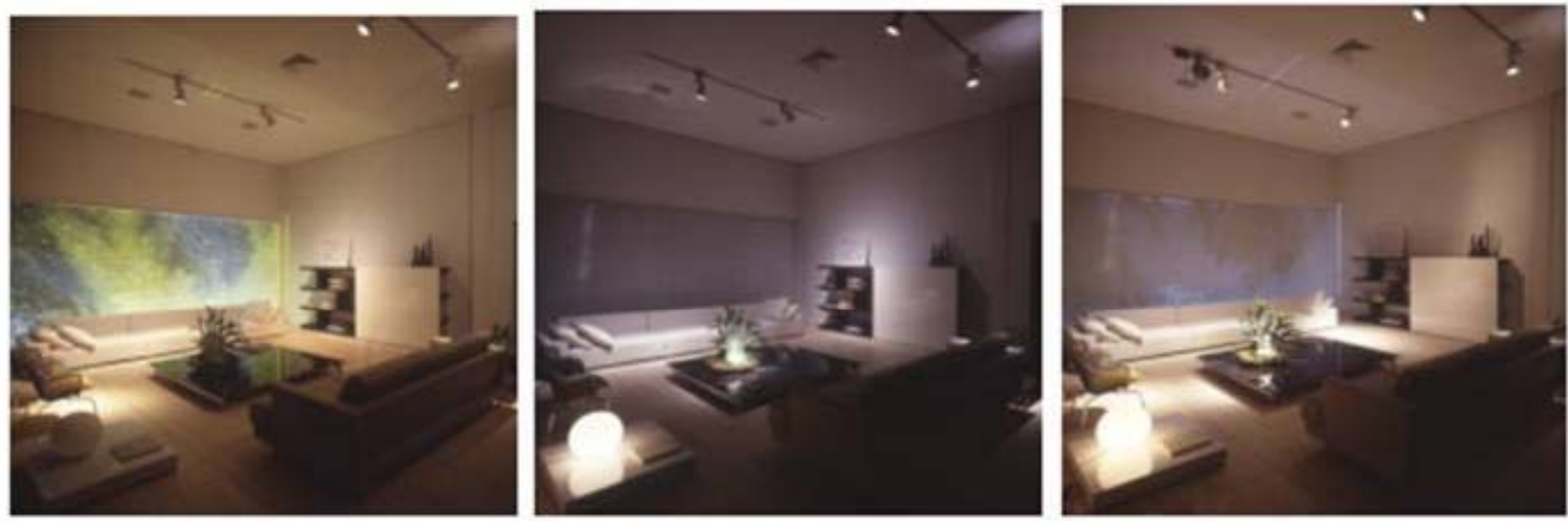

Fig.2 - Cenários de iluminação

A criação de cenários de iluminação ou a variação da iluminação de acordo com as necessidades ou de acordo com a iluminação natural existente cria uma sensação de conforto, flexibilidade e eficiência da instalação.

A segurança é um outro sistema que deve ser considerado.

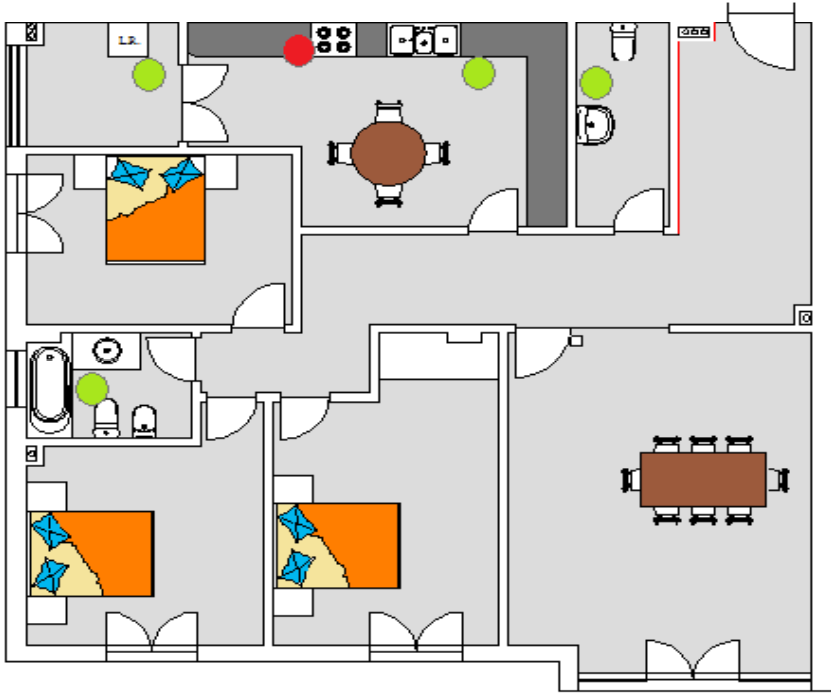

Detector de gás
Os três sistemas que se falaram anteriormente são os que usualmente são dotados de "inteligência” numa habitação. Também começa a ser usual querer comandar alguns circuitos de potência, por exemplo o circuito em que está ligada a televisão ou as máquinas de lavar roupa ou louça, ou pode ter interesse comandar algumas tomadas, ou até a difusão sonora, ou o aquecimento. Contudo, apesar de quase todas as funções poderem ser dotadas de "inteligência", é preciso ter em atenção que quanto mais funções se pretenderem automatizar, mais cara ficará a instalação e a complexidade da mesma também aumenta.

\section{Tecnologia POWER LINE}

A tecnologia Powerline Carrier (PLC) usa a cablagem tradicional de uma instalação (circuitos de tomadas e iluminação) para enviar as mensagens entre os emissores e os receptores. É enviado um sinal modulado em frequência (normalmente superior a $100 \mathrm{kHz}$ ) pelos condutores eléctricos da instalação e apenas os receptores programados para esses sinais poderão actuar de acordo com esse sinal. 
Como esta tecnologia usa a cablagem da instalação eléctrica da habitação, é preciso ter em atenção que como as instalações estão ligadas pela mesma cablagem eléctrica, um sistema instalado numa habitação poderá comunicar com a instalação do vizinho. Para evitar esse tipo de situações é conveniente a instalação de filtros no quadro eléctrico de entrada da habitação. Existem já sistemas desenvolvidos em que os aparelhos são dotados de um endereço, um código único para cada aparelho. Nesse tipo de sistemas a necessidade de filtros é menor. Os sistemas mais actuais também combinam a tecnologia de infra vermelhos (IR) e rádio frequencia (RF) com a tecnologia PLC. Com esta combinação de sistemas a flexibilidade da instalação aumenta. Por exemplo é possivel com um comando IR ou RF dar ordem a um estore para abrir ou fechar ou gerar um cenário de iluminação numa sala.

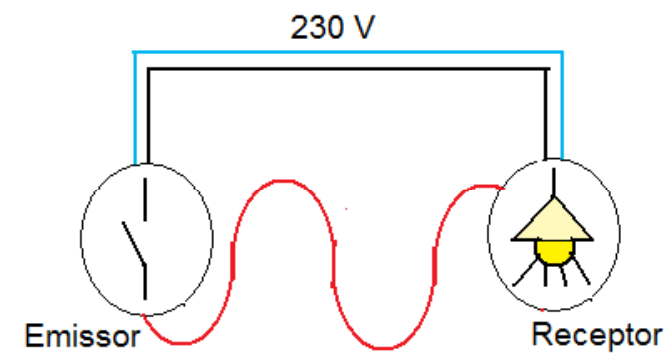

Fig.4 - Comunicação PLC

Uma vantagem deste tipo de instalações é que elas não são estáticas, isto é, se num determinado momento quisermos que um determinado comando deixe de fazer a sua função para passar a fazer outra, não é necessário alterar a aparelhagem mas apenas alterar a sua programação. Como não são sistemas muito complicados, a programação também é fácil de entender e efectuar. Geralmente é feita com recurso a apenas a uma chave de fendas e à manobra de alguns switchs.

Uma outra vantagem deste tipo de sistemas é que não é necessário alterar toda a instalação. É possível dotar de "inteligência" apenas algumas divisões de uma habitação, continuando o resto da habitação a usar a instalação tradicional. Esta é uma vantagem importante porque anula a ideia de que este tipo de sistemas são demasiadamente caros. Como não é necessário aplicar a tecnologia a toda a instalação, ela pode ser aplicada de acordo com as necessidades ou de acordo com a disponibilidade monetária do proprietário da instalação.

Como se tenta demonstrar na figura 5, apenas na sala está aplicado o sistema de domótica para comando da iluminação e criação de cenários de iluminação, a restante instalação eléctrica continua a ser a tradicional.

Uma limitação de alguns destes sistemas PLC é que a transmissão do sinal pode ser feito através do condutor neutro, o que implica a iunstalação de mais um condutor de neutro em algumas situações.

Quanto ao design e estética dos aparelhos, que antigamente eram diferentes dos aparelhos de comando da instalação tradicional, hoje em dia esse problema desapareceu. Os fabricantes destes produtos investiram bastante neste aspecto e é fácil encontrar aparelhos de comando com design modernos e que não se diferenciam esteticamente da aparelhagem tradicional. Em algumas marcas, as diferenças existentes na aparelhagem não se conseguem notar exteriormente, pois quer os espelhos quer as teclas são as mesmas. A diferença está no mecanismo interno.

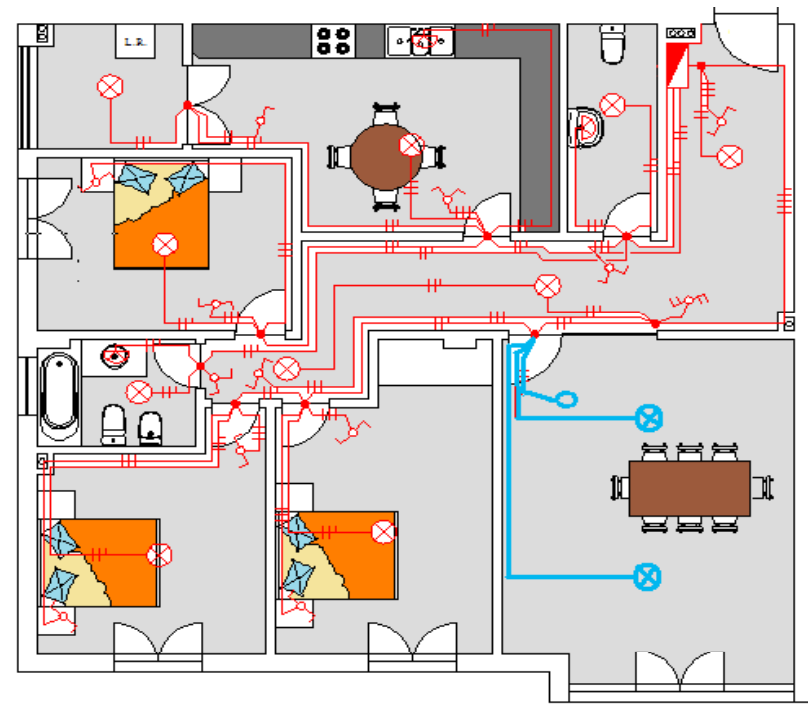

Fig.5 - Instalação tradicional e sistema PLC 


\section{ARTIGO TÉCNICO}

\section{Conclusão}

Neste artigo foi referido o sistema Powerline Carrier como alternativa aos sistemas de domótica pura.

Este sistema, apesar de não ter todas as funcionalidades que um sistema de domótica baseado na tecnologia EIB/KONNEX possibilita, conseguem automatizar e controlar as funções mais úteis numa instalação, tais como a iluminação, o comando de estores, o aquecimento e os alarmes técnicos. Uma vantagem dos sistemas PLC é a não necessidade de haver um bus dedicado à passagem da informação. As mensagens são enviadas pela cablagem tradicional da instalação eléctrica.

Apesar de estes sistemas poderem ser utilizados como upgrades às instalações tradicionais, sem haver a necessidade de fazer uma nova instalação eléctrica, para se tirar todo o partido das vantagens que estes sistemas permitem, o ideal seria os projectistas eléctricos dimensionarem as instalações para este tipo de sistemas ao nível do projecto eléctrico.

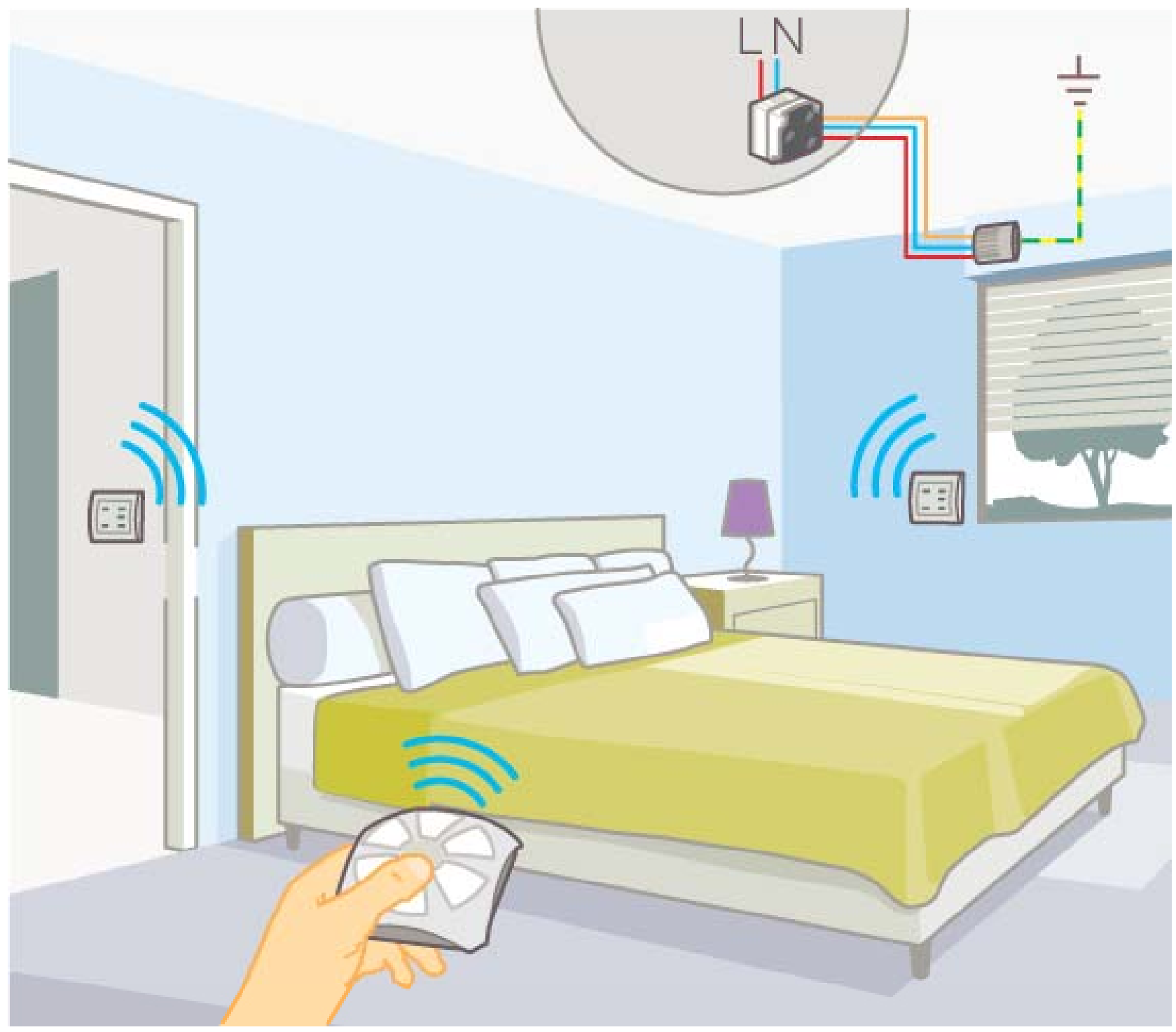

